\title{
A COMPARATIVE STUDY ON EFFICACY AND SAFETY OF TOLPERISONE VERSUS TIZANIDINE IN PATIENTS SUFFERING FROM ACUTE LOW BACK PAIN WITH MUSCLE SPASM
}

\author{
ABDUL FAHEEM KHAN ${ }^{1}$, KHANETA PARVEEN ${ }^{2 *}$ \\ ${ }^{1}$ Department of Pharmacology, Chirayu Medical College and Hospital, Bhopal, Madhya Pradesh, India. ${ }^{2}$ Department of Pathology, Chirayu \\ Medical College and Hospital, Bhopal, Madhya Pradesh, India. E-mail: drkhaneta@gmail.com
}

Received: 03 October 2021, Revised and Accepted: 15 November 2021

\section{ABSTRACT}

OBJECTIVES: The objectives of this study were to compare the efficacy and safety of Tolperisone tablets $50 \mathrm{mg}$ three times daily versus Tizanidine $2 \mathrm{mg}$ tablets thrice daily for the treatment of acute low back pain with muscle spasm.

METHODS: The comparative study was carried out in 50 patients from orthopedics Dr. Pinnamaneni Siddhartha Institute of Medical Sciences and Research Foundation, Vijayawada. Only those patients fulfilling the inclusion/exclusion criteria were enrolled into the study. Participants suffering from acute low back pain with muscle spasm were divided into two groups. The participants were followed up on Day-14 as final analysis.

RESULTS: Subjects receiving Tolperisone showed a mean value of $16.43 \pm 1.16$ in the Roland Morris low back pain and disability questionnaire both groups on day 1 and was reduced to $7.82 \pm 1.15(51.94 \%)$ on day 7 and $2.56 \pm 1.53(84.46 \%)$ on day 14. Similarly, the patients in the tizanidine group had mean value of $15.93 \pm 1.61$ on day 1 , which was reduced to $6.77 \pm 1.68(57.64 \%)$ on day 7 , and $2.88 \pm 1.92(81.95 \%)$ on day 14 , as comparable to the Tolperisone group. There was no statistically significant difference between the two groups, $(p>0.05)$ for pain at rest, pain at night, restrictions of movement, changes in stiffness, changes in numbness, and changes in tenderness. There was a statistically significant difference between the two groups, $(\mathrm{p}<0.05)$ for pain on movement and kinesalgia.

CONCLUSIONS: Tolperisone was found comparable in efficacy to Tizanidine in improving the clinical symptoms of changes in pain Self-assessment by the patient on different applied parameters.

Keywords: Tolperisone, Low back pain, Tizanidine, Muscle spasm.

(C) 2021 The Authors. Published by Innovare Academic Sciences Pvt Ltd. This is an open access article under the CC BY license (http://creativecommons.org/ licenses/by/4.0/) DOI: http://dx.doi.org/10.22159/ajpcr.2021v14i12.43295. Journal homepage: https://innovareacademics.in/journals/index.php/ajpcr

\section{INTRODUCTION}

Acute Low back pain (ALBP) associated with muscle spasm is an involuntary, painful contraction of muscles that interferes with the function and cause of the muscular disorder. The use of centrally acting skeletal muscle relaxants, though efficacious, is associated with frequent development of dose-related adverse drug reactions like sedation, impairment of voluntary motor functions, and ataxia. Hence, there is a need for newer better drugs for the treatment of conditions associated with muscle spasm $[1,2]$.

The estimated worldwide lifetime prevalence of low back pain varies from $50 \%$ to $84 \%$. The occurrence of low back pain in India is also alarming with nearly $60 \%$ of the people in India have suffered from low back pain at some time during their lifespan [2-4].

The current clinical evidence of acute low back pain supports the use of centrally acting muscle relaxant alone or in combination with NSAIDs. Acute Low back pain (ALBP), a high prevalent condition, is usually associated with 'muscle spasm' that is giving rise to pain and stiffness. Tolperisone hydrochloride, a piperidine derivative, is centrally acting muscle relaxant used for treatment muscle spasm associated and pain. We also sought to draw a conclusion whether Tolperisone finds its place in the treatment of acute LBP and thus aiding the clinicians in choosing the appropriate drug for acute LBP associated with muscle spasm [3-5].

\section{Objectives}

To compare the efficacy and safety of Tolperisone hydrochloride tablets $50 \mathrm{mg}$ three times daily versus Tizanidine $2 \mathrm{mg}$ tablets thrice daily for the treatment of patients suffering from acute low back pain with muscle spasm.

\section{METHODS}

The study was carried in 50 patients from Dr. Pinnamaneni Siddhartha Institute of Medical Sciences and Research Foundation (Dr. PSIMS \& RF) Vijayawada. Only patients satisfying the inclusion criteria were enrolled into the study. Potential study subjects were divided during the first visit to either of the two groups. The patients were then followed up on day- 14 .

Clinical diagnosis

Patients suffering from acute low back pain with muscle spasm.

\section{Selection criteria}

Inclusion criteria

Patients in the age group of 18-65 years, patients ready to give informed consent, and patients who were clinically stable with precise diagnosis.

\section{Exclusion criteria}

Pregnant or Lactating females, childbearing age. Patient with known suspected history of hypersensitivity to any of the trial drugs, impaired liver function, impaired kidney function, presence of active peptic ulcer or any other disease affecting the absorption of drug, hematologic or endocrine disorders. Patients already taking or have taken in the past the investigational medication. Back pain due to (Acute disc herniation, Osteoarthritis or Spinal stenosis, Spondylolisthesis, Ankylosing Spondylitis, Infection, and Malignancy).

\section{Study design}

Patients were randomly divided into two groups. Each patient as per randomization received tolperisone hydrochloride tablets or tizanidine tablets daily for a period of 14 days. 
Dosage

Patients randomized into two groups received Tolperisone $50 \mathrm{mg}$ or Tizanidine $2 \mathrm{mg}$ per day for a period of 14 days.

\section{Study schedule and plan}

The patients were enrolled after informed and written consent as per the inclusion and exclusion criteria. Current medical history and diagnosis were noted during the first visit. Patient was assigned to receive Tolperisone $50 \mathrm{mg}$ or Tizanidine $2 \mathrm{mg}$. After enrollment into study, follow-up was done on day 7. At the initial visit, following the general examination, blood sample was withdrawn to estimate $\mathrm{Hb}$, RBC, CBC, E.S.R, SGOT, total bilirubin, serum creatinine, and blood sugar (fasting). Similar procedure was repeated at the end of the treatment i.e., day- 7 and day-14.

\section{Administration of "Roland disability questionnaire" at the start and end of therapy}

This was a 24 point questionnaire and patient was instructed to mark the point when your back hurts with pain and mention the severity, type, duration, and many more parameters on all the three visits and at last, the mean value is calculated from all the three visit and statistics applied to observe the significant difference within the group from baseline to day 7 and day 14, and also compared between the two groups [6-10].

Patients were advised to maintain a "pain diary" which contains the different questions related to pain like when did the pain begin? When did the pain end, radiating or non-radiating?

The symptoms of back pain were scored based on the 'Visual Analogue Score' as 0-10 for severity (0-no pain, 1- mild discomfort, 2-moderate discomfort, 3-mild pain, 4-mild - moderate pain, 5 - moderate pain, 6moderate - severe pain, 7 - severe pain, 8 - very severe pain, 9 - very very severe pain, and 10-agony) [6-12].

\section{Clinical efficacy}

The symptoms of back pain were recorded as following parameters Pain at rest, Pain at night, Restriction of movement, Pain on movement, Stiffness, Numbness, Tenderness, and Kinesalgia. Visual Analogue Score from 0 to 10 for severity (0-no pain, 1-mild discomfort, 2-moderate discomfort, 3-mild pain, 4-mild - moderate pain, 5-moderate pain, 6-moderate - severe pain, 7-severe pain, 8-very severe pain, 9-very-very severe pain, and 10-agony). Rating Points were given to the patients' pain symptoms according to the severity on each visit and the mean value is calculated from each visit and compared to observe the statistically significant difference within the group and between the two groups.

Adverse effects if any were recorded in detail. Compliance was evaluated by asking the patient to bring balance medicine during follow-up visits. A minimum of $80 \%$ compliance was taken as satisfactory and only those patients with compliance more than $80 \%$ were considered for efficacy analysis.

The medication was prescribed to the patient and s/he was advised to report any adverse event, if any and return for follow-up on the assigned days. The patients were also being advised to report any symptomatic worsening of the disease.

\section{Assessment of safety}

All reported adverse drug reactions in the study population were analyzed for their severity, duration, and relation to the study drug.

\section{Statistical analysis}

The results were statistically analyzed by students $t$ test, paired $t$ test, wilcoxon signed rank test, Mann Whitney test, and Chi-square test.

\section{RESULTS}

Demographic Characteristics: Table 1 shows that mean age and average weight were comparable There were no dropouts in either group.
A total of 50 patients (25 in each group) completed the study and were included for statistical analysis.

\section{Efficacy parameters}

The efficacy parameters were changes in pain Self-assessment by the patient and the symptoms of back pain were recorded as following parameters Pain at rest, Pain at night, Restriction of movement, Pain on movement, Stiffness, Numbness, Tenderness, Kinesalgia. Visual analogue score (VAS) from 0 (absent) to 10 (severe) was measured as presence or absence.

As seen from Table 2 shows that the patients receiving Tolperisone showed a mean value of $16.48 \pm 1.15$ in the Roland Morris low back pain and disability questionnaire both groups on day 1 and was reduced to $7.92 \pm 1.15(51.94 \%)$ on day 7 and $2.56 \pm 1.53(84.46 \%)$ on day 14 . Similarly, in tizanidine group had mean value of $15.96 \pm 1.62$ on day 1 , which was reduced to $6.76 \pm 1.66(57.64 \%)$ on day 7 , and $2.88 \pm 1.92(81.95 \%)$ on day 14 , as comparable to Tolperisone group. There was no statistically significant difference between the two groups but there was statistically significant difference within the two groups $(\mathrm{p}<0.05)^{*}$

Table 3 describes the changes in different pain and stiffness parameters between the two groups.

\section{Changes in pain at rest}

Pain at rest was reduced from mean value of $2.6 \pm 0.57$ on day 1 to $1.24 \pm 0.43(52.30 \%)$ after 7 days of administration of Tolperisone, and $0.12 \pm 0.33(95.38 \%)$ after day 14 . Similarly, tizanidine reduced the pain at rest score from mean value of $3.4 \pm 1$ on day 1 to $1.88 \pm 1.23(44.70 \%)$ on day 7 , and further $0.68 \pm 1.06(80.0 \%)$ on day $14(\mathrm{p}>0.05)$. There was no statistical significant difference between the two groups, $(p>0.05)$, but there was statistical significant difference within the two groups $(\mathrm{p}<0.05)^{*}$

\section{Changes in pain at night}

In patients receiving Tolperisone, with a mean of $3.12 \pm 0.72$ showed pain at night on day 1 . Further, $0.8 \pm 0.91(74.35 \%)$ showed improvement in pain at night on day 7 , and $0.04 \pm 0.2(98.71 \%$ ) improvement on Day 14 , In patients receiving tizanidine, $3.04 \pm 0.73$ showed pain at night on day 1 , followed by $0.56 \pm 0.76(81.57 \%)$ improvement on day 7 , and

Table 1: Demographic profile

\begin{tabular}{lll}
\hline Parameters & Tolperisone & Tizanidine \\
\hline $\begin{array}{l}\text { No. of patients } \\
\text { Age (years) }{ }^{\mathrm{a}}\end{array}$ & 25 & 25 \\
$\quad$ Mean $\pm \mathrm{SD}$ & $55.24 \pm 4.05$ & $55.88 \pm 3.04$ \\
$\quad$ Range & $18-65$ years & $18-65$ years \\
Weight $(\mathrm{kg})^{\mathrm{a}}$ & & \\
$\quad$ Mean $\pm \mathrm{SD}$ & $69.44 \pm 3.92$ & $69.48 \pm 2.31$ \\
Range & $42-76 \mathrm{~kg}$ & $38-78 \mathrm{~kg}$ \\
Sex $(\%)^{\mathrm{b}}$ & & \\
$\quad$ Male & 13 & 9 \\
Female & 12 & 16 \\
\hline p $>0.05$ there was no statistically Significant difference between the two groups
\end{tabular}

Table 2: Comparison of changes in pain self-assessment by Roland Morris low back pain and disability questionnaire in both groups

\begin{tabular}{lll}
\hline Duration in days & Tolperisone & Tizanidine \\
\hline Basal & $16.48 \pm 1.15$ & $15.96 \pm 1.62$ \\
Day 7 & $7.92 \pm 1.15(51.94 \%)^{*}$ & $6.76 \pm 1.66(57.64 \%)^{*}$ \\
Day 14 & $2.56 \pm 1.53(84.46 \%)$ & $2.88 \pm 1.92(81.95 \%)$ \\
\hline
\end{tabular}

$p>0.05$ there was no statistically Significant difference between the two groups. ${ }^{*} p<0.05$ there was statistically significant difference within the two groups 
Table 3: Comparison of different pain and stiffness parameters

\begin{tabular}{|c|c|c|c|}
\hline Duration in days & Tolperisone & Tizanidine & p value \\
\hline \multicolumn{4}{|c|}{ Changes in pain at rest } \\
\hline Basal & $2.6 \pm 0.57$ & $3.4 \pm 1$ & \multirow{3}{*}{$\mathrm{p}>0.05$ between the two groups. ${ }^{*} \mathrm{p}<0.05$ within the two groups } \\
\hline Day 7 & $1.24 \pm 0.43(52.30 \% *)$ & $1.88 \pm 1.23(44.70 \%)^{*}$ & \\
\hline Day 14 & $0.12 \pm 0.33(95.38 \%)$ & $0.68 \pm 1.06(80.0 \%)$ & \\
\hline \multicolumn{4}{|c|}{ Changes in pain at night } \\
\hline Basal & $3.12 \pm 0.72$ & $3.04 \pm 0.73$ & \multirow[t]{2}{*}{$\mathrm{p}>0.05$ between the two groups. ${ }^{*} \mathrm{p}<0.05$ within the two groups } \\
\hline Day 7 & $0.8 \pm 0.91(74.35 \%)^{*}$ & $0.56 \pm 0.76(81.57 \%)^{*}$ & \\
\hline \multicolumn{4}{|c|}{ Changes in restriction of movement } \\
\hline Basal & $3.8 \pm 0.5$ & $4.32 \pm 0.9$ & \multirow[t]{3}{*}{$\mathrm{p}>0.05$ between the two groups. ${ }^{*} \mathrm{p}<0.05$ within the two groups } \\
\hline Day 7 & $1.8 \pm 0.64(52.63 \%) *$ & $2.36 \pm 1.03(45.37 \%)^{*}$ & \\
\hline Day 14 & $0.56 \pm 0.58(85.26 \%)$ & $0.84 \pm 0.94(80.55 \%)$ & \\
\hline \multicolumn{4}{|c|}{ Changes in pain of movement } \\
\hline Basal & $3.96 \pm 0.35$ & $4.72 \pm 1.17$ & \multirow[t]{3}{*}{$\mathrm{p}<0.05$ between the two groups. ${ }^{*} \mathrm{p}<0.05$ within the two groups } \\
\hline Day 7 & $1.72 \pm 0.45(56.56 \%)^{*}$ & $2.44 \pm 1.26(48.30 \%)^{*}$ & \\
\hline Day 14 & $0.48 \pm 0.50(87.87 \%)$ & $0.84 \pm 1.17(82.20 \%)$ & \\
\hline \multicolumn{4}{|l|}{ Changes in stiffness } \\
\hline Basal & $4.32 \pm 0.80$ & $3.92 \pm 0.4$ & \multirow[t]{3}{*}{$\mathrm{p}>0.05$ between the two groups. ${ }^{*} \mathrm{p}<0.05$ within the two groups } \\
\hline Day 7 & $2.16 \pm 0.98(50.0 \%)$ & $1.84 \pm 0.55(53.06 \%)$ & \\
\hline Day 14 & $0.84 \pm 1.02(80.55 \%)^{*}$ & $0.72 \pm 0.54(81.63 \%)^{*}$ & \\
\hline \multicolumn{4}{|c|}{ Changes in numbness } \\
\hline Basal & $2.28 \pm 0.61$ & $2.6 \pm 0.70$ & \multirow[t]{3}{*}{$\mathrm{p}>0.05$ between the two groups. ${ }^{*} \mathrm{p}<0.05$ within the two groups } \\
\hline Day 7 & $1 \pm 0.57(56.14 \%)$ & $1.6 \pm 0.70(38.46 \%)^{*}$ & \\
\hline Day 14 & $0.2 \pm 0.40(91.22 \%)^{*}$ & $0.72 \pm 0.73(72.30 \%)$ & \\
\hline \multicolumn{4}{|c|}{ Changes in tenderness } \\
\hline Basal & $5.28 \pm 0.54$ & $5.72 \pm 0.73$ & \multirow[t]{3}{*}{$\mathrm{p}>0.05$ between the two groups. ${ }^{*} \mathrm{p}<0.05$ within the two groups } \\
\hline Day 7 & $2.6 \pm 0.64(50.75 \%)^{*}$ & $3.04 \pm 0.97(46.85 \%)$ & \\
\hline Day 14 & $1 \pm 0.5(81.06 \%)$ & $1.52 \pm 1.04(73.42 \%)$ & \\
\hline \multicolumn{4}{|c|}{ Changes in kinesalgia } \\
\hline Basal & $2.36 \pm 0.7$ & $4 \pm 1$ & \multirow[t]{3}{*}{$\mathrm{p}<0.05$ between the two groups. ${ }^{*} \mathrm{p}<0.05$ within the two groups } \\
\hline Day 7 & $1.08 \pm 0.4(54.23 \%)$ & $2.28 \pm 1.24(43.0 \%)$ & \\
\hline Day 14 & $0.16 \pm 0.37(93.22 \%)^{*}$ & $1.04 \pm 1.20(74.0 \%)^{*}$ & \\
\hline
\end{tabular}

$0.12 \pm 0.33(96.05 \%)$ improvement on day 14 . There was no statistical significant difference between the two groups, $(p>0.05)$, but there was statistical significant difference within the two groups $(\mathrm{p}<0.05)^{*}$.

\section{Changes in restriction of movement}

In patients receiving Tolperisone, with a mean of $3.8 \pm 0.5$ showed restriction of movement on Day 1. Further, with a mean $1.8 \pm 0.64(52.63 \%)$ showed improvement in restriction of movement on day 7 , and $0.56 \pm 0.58(85.26 \%)$ on day 14 , In patients receiving tizanidine, with a mean of $4.32 \pm 0.9$ showed restriction of movement on Day 1, followed by $2.36 \pm 1.03$ (45.37\%) improvement on Day 7, and $0.84 \pm 0.94(80.55 \%)$ on Day 14 . There was no statistical significant difference between the two groups, $(p>0.05)$, but there was statistical significant difference within the two groups $(\mathrm{p}<0.05)^{*}$.

\section{Changes in pain of movement}

In patients receiving Tolperisone, with a mean of $3.96 \pm 0.351$ show pain of movement on day 1. Further, $1.72 \pm 0.45(56.56 \%)$ showed improvement in pain of movement on day 7 , and $0.48 \pm 0.50(87.87 \%)$ on Day 14. In patients receiving tizanidine, $4.72 \pm 1.17$ show pain of movement on Day 1, followed by $2.44 \pm 1.26$ (48.30\%) improvement on day 7 , and $0.84 \pm 1.17(82.20 \%)$ improvement on day 14 . There was statistical significant difference between the two groups, $(\mathrm{p}<0.05)$, and also there was statistical significant difference within the two groups $(\mathrm{p}<0.05)^{*}$

\section{Changes in stiffness}

In patients receiving Tolperisone, with a mean value of $3.92 \pm 0.4$ showed stiffness on Day 1. Further, $1.84 \pm 0.55$ (53.06\%) showed improvement in stiffness on Day 7, and 1.84 $\pm 0.55(81.63 \%)$ improved on Day 14 . In patients receiving tizanidine, $4.32 \pm 0.80$ showed stiffness on Day 1 , followed by $2.16 \pm 0.98(50.0 \%)$ showed improvement on Day 7 , and $0.84 \pm 1.028(80.55 \%)$ improved on Day 14 . There was no statistically significant difference between the two groups, ( $p>0.05)$, but there was statistical significant difference within the two groups $(\mathrm{p}<0.05)^{*}$.

\section{Changes in numbness}

In patients receiving Tolperisone, with a mean of $2.28 \pm 0.61$ showed numbness on Day 1. Further, $1 \pm 0.57$ (56.14\%) showed improvement in numbness on Day 7, and 0.2 \pm 0.40 (91.22\%) improved on day 14 . In patients receiving tizanidine, $2.6 \pm 0.70$ showed numbness on day 1 , followed by $1.6 \pm 0.70$ (38.46\%) showed improvement on Day 7, and $0.72 \pm 0.73(72.30 \%)$ improved on day 14 . There was no statistical significant difference between the two groups, $(p>0.05)$, but there was statistical significant difference within the two groups $(\mathrm{p}<0.05)^{*}$.

\section{Changes in tenderness}

In patients receiving Tolperisone, with a mean of $5.28 \pm 0.54$ showed tenderness on day 1 . Further, $2.6 \pm 0.64(50.75 \%)$ showed improvement in tenderness on day 7 , and $1 \pm 0.5(81.06 \%)$ improved on day 14. In patients receiving tizanidine, $5.72 \pm 0.73$ showed tenderness on Day 1, followed by $3.04 \pm 0.97$ (46.85\%) showed improvement on day 7 , and $1.52 \pm 1.04(73.42 \%)$ improved on day 14. There was no statistical significant difference between the two groups, $(p>0.05)$, but there was statistical significant difference within the two groups $(\mathrm{p}<0.05)^{*}$.

\section{Changes in kinesalgia}

In patients receiving Tolperisone, with a mean of $2.36 \pm 0.7$ showed Kinesalgia on day 1. Further, 1.08 \pm 0.4 (54.23\%) showed improvement in Kinesalgia on Day 7, and $0.16 \pm 0.37$ (93.22\%) improved on day 14. In patients receiving tizanidine, $4 \pm 1$ showed Kinesalgia on day 1 , followed by $2.28 \pm 1.24(43.0 \%)$ showed improvement on day 7 , and $1.04 \pm 1.20(74.0 \%)$ improved on day 14 . There was statistical significant difference between the two groups, $(\mathrm{p}<0.05)$, and also was statistical significant difference within the two groups $(\mathrm{p}<0.05)^{*}$. 
Table 4: Efficacy and tolerability by physicians and patients

\begin{tabular}{|c|c|c|c|c|c|}
\hline & \multicolumn{2}{|c|}{ Tolperisone } & \multicolumn{2}{|c|}{ Tizanidine } & \multirow[t]{2}{*}{ p value } \\
\hline & $\mathbf{n}$ & $\%$ & $\mathbf{n}$ & $\%$ & \\
\hline \multicolumn{6}{|c|}{ Overall assessment of efficacy of treatment by physicians } \\
\hline Good & 09 & 37.5 & 16 & 66.66 & \multirow{3}{*}{$\mathrm{p}>0.05$, between the two groups. } \\
\hline Poor & 00 & 00 & 01 & 4.16 & \\
\hline Total & 24 & 100 & 24 & 100 & \\
\hline \multicolumn{6}{|c|}{ Overall assessment of efficacy of treatment by patients } \\
\hline Excellent & 17 & 70.83 & 07 & 29.16 & \multirow[t]{4}{*}{$\mathrm{p}<0.05$, between the two groups. } \\
\hline Good & 07 & 29.16 & 14 & 58.33 & \\
\hline Poor & 00 & 00 & 03 & 12.5 & \\
\hline Total & 24 & 100 & 24 & 100 & \\
\hline \multicolumn{6}{|c|}{ Overall assessment of tolerability of treatment by physicians } \\
\hline Excellent & 17 & 70.83 & 05 & 20.83 & \multirow[t]{4}{*}{$\mathrm{p}<0.05$, between the two groups. } \\
\hline Good & 05 & 20.83 & 14 & 58.33 & \\
\hline Poor & 02 & 8.33 & 05 & 20.83 & \\
\hline Total & 24 & 100 & 24 & 100 & \\
\hline Excellent & 17 & 70.83 & 06 & 25.0 & \multirow[t]{4}{*}{$\mathrm{p}<0.05$, between the two groups. } \\
\hline Good & 05 & 20.83 & 11 & 45.83 & \\
\hline Poor & 02 & 8.33 & 07 & 29.16 & \\
\hline Total & 24 & 100 & 24 & 100 & \\
\hline
\end{tabular}

\section{Efficacy assessment}

According to investigator assessment for efficacy (Table 4) 15 (62.5\%) of total cases had an "excellent" improvement followed by 09 (37.5\%) "good" in Tolperisone. In tizanidine group, only 07 (29.16\%) of total cases had an "excellent" improvement followed by 16 (66.66\%) "good" and 01 (4.16\%) "poor".

Table 4 as per the patient's own assessment, 17 (70.83\%) of total cases was rated "excellent", 07 (29.16\%) "good" and 00 (0\%) "poor" in Tolperisone. In the tizanidine group 07 (29.16\%) of total cases was rated "excellent" and 14 (58.33\%) as "good" and 03 (12.5\%) as "poor."

\section{Tolerability assessment}

According to physicians' assessment for tolerability (Table 4) $17(70.83 \%)$ of the total cases had "excellent" safety and $05(20.83 \%)$ showed "good" safety and $02(8.33 \%)$ as "poor" in group Tolperisone. In the tizanidine group, 05 (20.83\%) of total cases was rated "excellent" and 14 (58.33\%) as "good" and 05 (20.83\%) as "poor."

According to patient's assessment for tolerability (Table 4), 17 (70.83\%) of the total cases had "excellent" safety and 05 (20.83\%) showed "good" safety and $02(8.33 \%)$ as "poor" in group Tolperisone. In the tizanidine group, $06(25.0 \%)$ of total cases were rated "excellent" and 11 (45.83\%) as "good" and 07 (29.16\%) as "poor."

\section{DISCUSSION}

The results of five studies ( 3 RCTs and 2 case series) suggest that Tolperisone intervention (7-14 days) may be effective in patients with acute LBP compared to placebo/thiocolchicoside/diazepam [3-5] and in before and after treatment studies [6,7]

Tolperisone intervention improved both pain and physiological measures in acute LBP patients. Treatment with Tolperisone for 4 weeks in chronic LBP patients also improved the pain; non-significant to McKenzie therapy and like tizanidine [8-10].

Regarding safety and tolerability, the incidence of AEs was significantly less in acute LBP patients treated with Tolperisone when compared to those treated with thiocolchicoside and diazepam. In a placebocontrolled trial [8], a smaller number of acute LBP patients $(n=22)$ experienced AEs in Tolperisone group as compared to placebo $(n=29)$. This may be because average consumption of rescue (paracetamol $500 \mathrm{mg}$ ) medication was significantly higher in the placebo group.
Chronic LBP patients on Tolperisone (16.6\%) showed numerically less dropouts due to AEs compared to tizanidine (30\%), and a better adherence to the therapy $[9,10]$.

Since, the evidence from the present review on the efficacy of Tolperisone for acute/chronic LBP is of low to moderate quality due to the small number of included studies and short duration, it is therefore difficult for us to suggest a definitive conclusion for the role of tolperiosne in the treatment of LBP $[11,12]$. Our results indicate that Tolperisone is an effective muscle relaxant drug with similar clinical benefits to that of other molecules, such as Tizanidine, which are currently used in the management of acute low back pain due to a contraction of spinal muscles. Tolperisone is a muscle relaxant compound with a pattern of activities slightly different from that of Tizanidine [11-13].

\section{Limitations of the study}

The present study reveals that Tolperisone may be effective in improving pain and physiological outcomes in acute LBP patients. However, due to a small number of patients, more well-designed RCTs of good quality with a larger sample size and longer follow-up period are needed to confirm the clinical benefits of Tolperisone in the treatment of acute or chronic LBP with or without spasm.

\section{CONCLUSIONS}

Tolperisone was found to be comparable to Tizanidine in improving symptoms of changes in pain Self-assessment by the patient on different applied parameters. The compliance of Tolperisone was found to be satisfactory. The global assessment for efficacy and safety for Tolperisone was found comparable to tizanidine.

\section{ACKNOWLEDGMENTS}

I acknowledge and thank to all my co-authors, the department of orthopedics at Dr. PSIMS and RF for supporting me in patient enrollment and paramedical staff and study participants.

\section{AUTHORS CONTRIBUTION}

All authors have contributed to study design, manuscript writing and review, data analysis and article finalization.

\section{CONFLICT OF INTEREST}

None. 


\section{AUTHOR FUNDING OR AUTHOR SPONSORSHIP}

None.

\section{REFERENCES}

1. Soonawalla DF, Joshi N. Efficacy of thiocolchicoside in Indian patients suffering from low back pain associated with muscle spasm. J Indian Med Assoc 2008;106:331-5.

2. Ahdhi GS, Subramanian R, Saya GK, Yamuna TV. Prevalence of low back pain and its relation to quality of life and disability among women in rural area of Puducherry, India. Indian J Pain 2016;30:111-5.

3. Sartini S, Guerra L. Open experience with a new myorelaxant agent for low back pain. Adv Ther 2008;25:1010-8.

4. Sakai Y, Matsuyama Y, Nakamura H, Katayama Y, Imagama S, Ito Z, et al. The effect of muscle relaxant on the paraspinal muscle blood flow: A randomized controlled trial in patients with chronic low back pain. Spine 2008;33:581--7.

5. Golovacheva VA, Golovacheva AA, Zinovyeva OE, Golubev VL. Tolperisone in the treatment of acute and chronic nonspecific back pain. Neurol Neuropsychiatry Psychosomatics 2020;12:137-42.
6. Vaughan SA, Torres K, Kaye R. RESUME-1: A phase III study of tolperisone in the treatment of painful, acute muscle spasms of the back. Pain Manag 2021. (Epub ahead of print).

7. Svyrydova N. Back pain treatment: A review of the 2018 recommendations. East Eur J Neurol 2018;3:33-43.

8. Pratzel HG, Alken RG, Ramm S. Efficacy and tolerance of repeated oral doses of tolperisone hydrochloride in the treatment of painful reflex muscle spasm: Results of a prospective placebo-controlled double-blind trial. Pain 1996;67:417-25.

9. Chou R, Peterson K, Helfand M. Comparative efficacy and safety of skeletal muscle relaxants for spasticity and musculoskeletal conditions: A systematic review. J Pain Symptom Manage 2004;28:140-75.

10. See S, Ginzburg R. Skeletal muscle relaxants. Pharmacotherapy 2008;28:207-13.

11. See S, Ginzburg R. Choosing a skeletal muscle relaxant. Am Fam Physician 2008;78:365-70.

12. Lataste X, Emre M, Davis C, Groves L. Comparative profile of tizanidine in the management of spasticity. Neurology 1994;44 11 Suppl 9:S53-9.

13. Elenbaas JK. Centrally acting oral skeletal muscle relaxants. Am J Hosp Pharm 1980;37:1313-23. 